\title{
Complex Nature of Neural Tube Defects: A Regional Experience
}

\section{Emrah TURHAN', Fusun G. VAROL ${ }^{1}$, Hakan GURKAN², Cenk N. SAYIN ${ }^{1}$}

\section{ABSTRACT}

OBJECTIVE: The underlying gene-environment interaction of fetal neural tube defects is affected by several factors including geography, ethnicity and time. Local features of fetal neural tube defects were described.

STUDY DESIGN: A prospective cohort study of 48 fetal neural tube defects in a single tertiary medical center at the northwestern region of Turkey (2013-2015) was done via ultrasound, magnetic resonance imaging (MRI), conventional karyotyping, maternal methylenetetrahydrofolate reductase c.677C $>\mathrm{T}$ (rs1801133) single-nucleotide polymorphism and maternal serum levels of folic acid, vitamin B12 and zinc. For comparison of means, a Student's T-Test was used.

RESULTS: The prevalence of neural tube defects was 11.4 per 10000 births (48/42000) in northwestern Turkey. The defects on the cranium $(n=23 ; 47.9 \%)$ and spine $(n=25 ; 52.1 \%)$ were ultrasonographically detected. MRI did not give additional benefit over the ultrasonography. The ratio of associated anomalies in neural tube defect group was $25 \%$. Two fetal neural tube defects with Down syndrome were remarkable. The rate of homozygous methylenetetrahydrofolate reductase c.677C $>$ T SNPs among the mothers of neural tube defect fetuses $(n=20)$ was $15 \%$. Comparing with gestationally matched healthy pregnancies, although maternal BMls and periconceptional folate intake of neural tube defect group were significantly different, maternal serum folic acid, vitamin B12 and zinc levels were similar.

CONCLUSION: The northwestern region appeared to be a relatively low prevalence area of Turkey for fetal neural tube defects. Any association with maternal serum folic acid, vitamin B12 and zinc levels could not be shown in this region.

Keywords: Fetal neural tube defects, Phenotype, Ultrasonography, Methylenetetrahydrofolate reductase, Folic acid

Gynecol Obstet Reprod Med 2018;24(3):119-123

\section{Introduction}

Neural tube defects (NTD) are a group of birth defects caused by a failure of neural tube closure. The underlying gene-environment interaction is influenced by several factors including geography, ethnicity and time (1). The prevalence of NTDs (1993-1994) in Turkey was found to be around 3 out of

${ }^{I}$ Trakya University Faculty of Medicine Departments of Obstetrics \& Gynecology, and ${ }^{2}$ Medical Genetics, Edirne, Turkey

Address of Correspondence: Fusun G. Varol

Trakya University Faculty of Medicine Department of Obstetrics \& Gynecology, 22030 Edirne, Turkey

fgvarol@yahoo.com

Submitted for Publication: $\quad 31.12 .2017$

Accepted for Publication: $\quad 28.01 .2018$

\begin{tabular}{|c|c|}
\hline & Access this article online \\
\hline $\begin{array}{c}\text { Quick Response Code: } \\
\text { Website: www.gorm.com.tr } \\
\text { e mail: info@gorm.com.tr }\end{array}$ \\
\cline { 2 - 2 }
\end{tabular}

How to cite this article: Turhan E. Varol FG. Gurkan H. Sayin CN. Complex Nature of Neural Tube Defects: A Regional Experience. Gynecol Obstet Reprod Med 2018;24(3):119-123 every 1000 births (2). This was increased significantly to 4.39 per 1000 births in the eastern Black Sea region after the Chernobyl nuclear power station accident (3). Elevated maternal serum alpha-fetoprotein levels and ultrasound scan (US) are the most important diagnostic aids in fetal NTD screening.

Periconceptional daily 400 microgram intake of folic acid (FA) lessened the rates of NTD to 0.6-1 per 1000 births (4). But another low risk population study could not show this relationship between MS folate, vitamin B12 (vit B12) during pregnancy (5). The role of serum zinc ( $\mathrm{Zn}$ ) levels during pregnancy is indispensable in the pathogenesis of NTDs (6). Maternal obesity, hyperinsulinemia is also found as strong risk factors for NTDs $(7,8)$. The results in the relationship between 5,10-methylenetetrahydrofolate reductase (MTHFR) c.677 C > T (rs1801133) single-nucleotide polymorphism (SNP) and NTD may remain controversial (9).

This study aimed to describe NTDs by using ultrasonography and fetal magnetic resonance imaging (MRI) and to analyze various maternal risk factors including demographics, body mass index (BMI), prenatal FA intake and bioassays of FA, vit B12, Zn and MTHFR c.677C > T (rs1801133) SNP. 


\section{Materials and Method}

\section{Participants}

This prospective cohort study of 48 fetuses with NTDs was conducted at a single tertiary medical center in the Thrace region of Turkey (2013-2015). The research was approved by the Institutional Ethics Committee (2013/27). The data obtained from 20 gestationally matched healthy pregnancies was used as controls for some demographics and serum analyses. Informed consent has been obtained from all pregnant women included in the study.

\section{Data collection and Measurements}

All the features of 48 fetuses with NTDs diagnosed by ultrasonography (Voluson 730 Pro, GE, Austria) were analyzed. Anterior curving of the cerebellar hemispheres with obliterated cisterna magna was defined as banana sign, frontal bossing of the cranium was known as lemon sign, both the cerebellum and brain stem extend into the foramen magnum was described as Chiari II. Fetal MRI (1.5T, GE, Virginia, USA) was employed for further evaluation of 6 NTDs (Figure 1).

Direct pregnancy interviews included questions about age, gravidity, parity, place of birth, height, weight, nutrition, periconceptional FA, Zn and vit B12 intake and family history.

Serum samples were obtained from each mother when the diagnosis of fetal NTD was confirmed and kept at $-80 \mathrm{oC}$ until assayed and analyzed for vit B12 and FA (Advia Centaur XP and Siemens) and Zn (Atomic Absorption Spectrophotometer, Shimadzu AA 6800). Maternal serum samples were also collected from 20 gestational age matched uncomplicated pregnancies, which constituted the control group.

Methylenetetrahydrofolate reductase c.677C $>\mathrm{T}$ (rs 1801133) single-nucleotide polymorphism was investigated in 20 mothers who had fetuses with NTDs and also had occlusive vascular complications in their family histories. Peripheral blood samples were drawn into 2 cc EDTA tubes and DNA isolation was performed using Qiagen DNA isolation kits (EZ1® DNA Blood $200 \mu \mathrm{L}$ Kit; Qiagen, Hilden, North Rhine-Westphalia, Germany) with an EZ1 Advanced XL (Qiagen) nucleic acid isolation system. DNA concentration and the purity of isolated DNA samples were measured using a NanoDrop device (NanoDrop 2000C; Thermo Fisher Scientific Inc., Wilmington, MA, USA). After measuring the concentration and purity, an amplification polymerase chain reaction (PCR) for pyro-sequencing was performed according to the manufacturer's recommended PCR protocol. A PyroMark PCR kit (Qiagen, Hilden, North Rhine-Westphalia, Germany) and primers in a PyroMark Custom Assay Kit (Qiagen) were used for detection of MTHFR c.677C > T SNP. The amplification PCR was performed with initial denaturation at $95^{\circ} \mathrm{C}$ for $15 \mathrm{~min}$. followed by 45 cycles at $94^{\circ} \mathrm{C}$ for 30 seconds, $60^{\circ} \mathrm{C}$ for 30 seconds and $72^{\circ} \mathrm{C}$ for 30 seconds, then a final extension at $72^{\circ} \mathrm{C}$ for $10 \mathrm{~min}$. After the PCR amplification, sequencing primers from a PyroMark Custom Assay Kit were used to pyro-sequence the PCR products and detect each polymorphism according to the manufacturer's instructions (PyroMark Q24 System; Qiagen, Hilden, North RhineWestphalia, Germany). The results were then analyzed using the PyroMark Q24 software system (Qiagen, Hilden, North Rhine-Westphalia, Germany), and the genotypes for polymorphisms were determined using samples from the NTD group (Qiagen, Hilden, North Rhine-Westphalia, Germany).

Conventional karyotyping $(n=12)$ was performed in the NTDs with additional anomalies. The results were evaluated by an IBM ${ }^{\circ}$ SPSS ${ }^{\circledR}$ (Statistical Package for the Social Sciences, California, USA). For comparison of means, a Student's T-Test was used for the parametric values. The statistical significance was defined as $\mathrm{p}<0.05$.

\section{Results}

\section{Population characteristics}

The age ( $26.3 \pm 5.5$ vs. $29 \pm 6.1)$ and gravidity ( $2.1 \pm 1.7$ vs. $1.8 \pm 1.1)$ of mothers of NTD group and controls were comparable ( $>0.05$ ). Maternal BMIs of NTD group (24.3 \pm 3.2$)$ were significantly higher than controls' $(22 \pm 2.6)$, but FA intake was lower in the NTD group ( $8 \%$ ) compared to the controls (40\%) $(p<0.05)$. There was no significant difference in serum FA, vit B12 or Zn levels between the women who had fetuses with NTDs and the controls (FA:12.6 \pm 6 vs.15.6 \pm 5.9 ), (vit B12: $222.6 \pm 111.8$ vs. $232.1 \pm 56)(\mathrm{Zn}: 153.2 \pm 77.2$ vs. $159.9 \pm 45.7)$ $(\mathrm{p}>0.05)$ (Table 1).

Table 1: Maternal characteristics and data about folate intake, serum folate, vitamin B12 and zinc levels in the groups (mean $\pm S D$ )

\begin{tabular}{lll}
\hline & $\begin{array}{l}\text { Neural Tube Defect } \\
(\mathrm{n}=48)\end{array}$ & $\begin{array}{l}\text { Controls } \\
(\mathrm{n}=20)\end{array}$ \\
\hline Age & $26.3 \pm 5.5$ & $29 \pm 6.1$ \\
Gravidity & $2.1 \pm 1.7$ & $1.8 \pm 1.1$ \\
BMI $(\mathrm{kg} / \mathrm{m} 2)^{*}$ & $24.3 \pm 3.2$ & $22 \pm 2.6$ \\
Folate intake $(\%)^{*}$ & 8 & 40 \\
Folate levels $(\mathrm{ng} / \mathrm{mL})$ & $12.6 \pm 6$ & $15.6 \pm 5.9$ \\
Vitamin B12 levels $(\mathrm{pg} / \mathrm{mL})$ & $222.6 \pm 111.8$ & $232.1 \pm 56$ \\
Zinc levels $(\mathrm{mg} / \mathrm{dL})$ & $153.2 \pm 77.2$ & $159.9 \pm 45.7$ \\
\hline
\end{tabular}




\section{Prevalence}

A total of 48 NTD cases were recorded in 42000 births in between 2013-2015 in Thrace. The prevalence of NTDs in northwestern Turkey was 11.4 per 10000 births (48/42000).

\section{Ultrasonographic features of NTDs}

Neural tube defects were countable as cranial $(n=23 ; 47.9 \%)$ and spinal $(n=25 ; 52.1 \%)$ which were referred at 12-21 gestational weeks (GW) with one exception, 37 weeks. The cranial defects included: acrania $(n=3 ; 13 \%)$, iniencephaly $(\mathrm{n}=2 ; 8.6 \%)$, anencephaly $(n=6 ; 26 \%)$, encephalocele $(n=10$; $43.4 \%)$ and exencephaly $(n=2 ; 8.6 \%)$. The spinal defects were at the thoracolumbar $(n=6 ; 24 \%)$, lumbar $(n=9$; $36 \%)$, lumbosacral ( $n=10 ; 40 \%)$ levels and $10.4 \%(n=5)$ of these cases had both cranial and spinal defects. These 5 cases were grouped in cranial defects. Prenatal ultrasonographic signs of the NTDs were ventriculomegaly $(n=17$; 68\%), "lemon" ( $\mathrm{n}=17 ; 68 \%)$ and "banana" signs $(\mathrm{n}=14 ; 56 \%)$. Ten $(40 \%)$ had all three signs and $22(88 \%)$ had at least one of these findings. Chiari II malformation was diagnosed in eight of the cases $(32 \%)$.

Fetal MRI was performed in 6 cases of the NTDs (Figure 1), however, no additional benefit could be obtained to the ultrasonography (10).

\section{NTD-associated anomalies}

According to prenatal and postnatal evaluations, 12 out of 48 fetuses with NTDs $(25 \%)$ had additional anomalies. These additional anomalies were cystic hygroma, low-set ears, micrognathia, heart anomalies, renal anomalies, diaphragmatic hernias, and genital and limb anomalies. Fetal conventional karyotyping was performed for these cases and revealed that two fetuses had Trisomy 21 whereas the others had normal karyotypes. One with Trisomy 21 exhibited low-set ears with a posterior encephalocele. The other Trisomy 21 showed lumbar spina bifida, low-set ears, ventricular septal defect and diaphragmatic hernia.

\section{MTHFR c.677C > T SNP in NTD group}

When we evaluated MTHFR c.677C $>$ T SNPs of twenty NTD mothers associated with occlusive vascular histories, we found no variation in two mothers $(10 \%)$ and homozygosity in three mothers (15\%), but heterozygosity in 15 mothers $(75 \%)$.

Figure 1: The findings of six fetuses with neural tube defects evaluated additionally by magnetic resonance imaging (MRI)
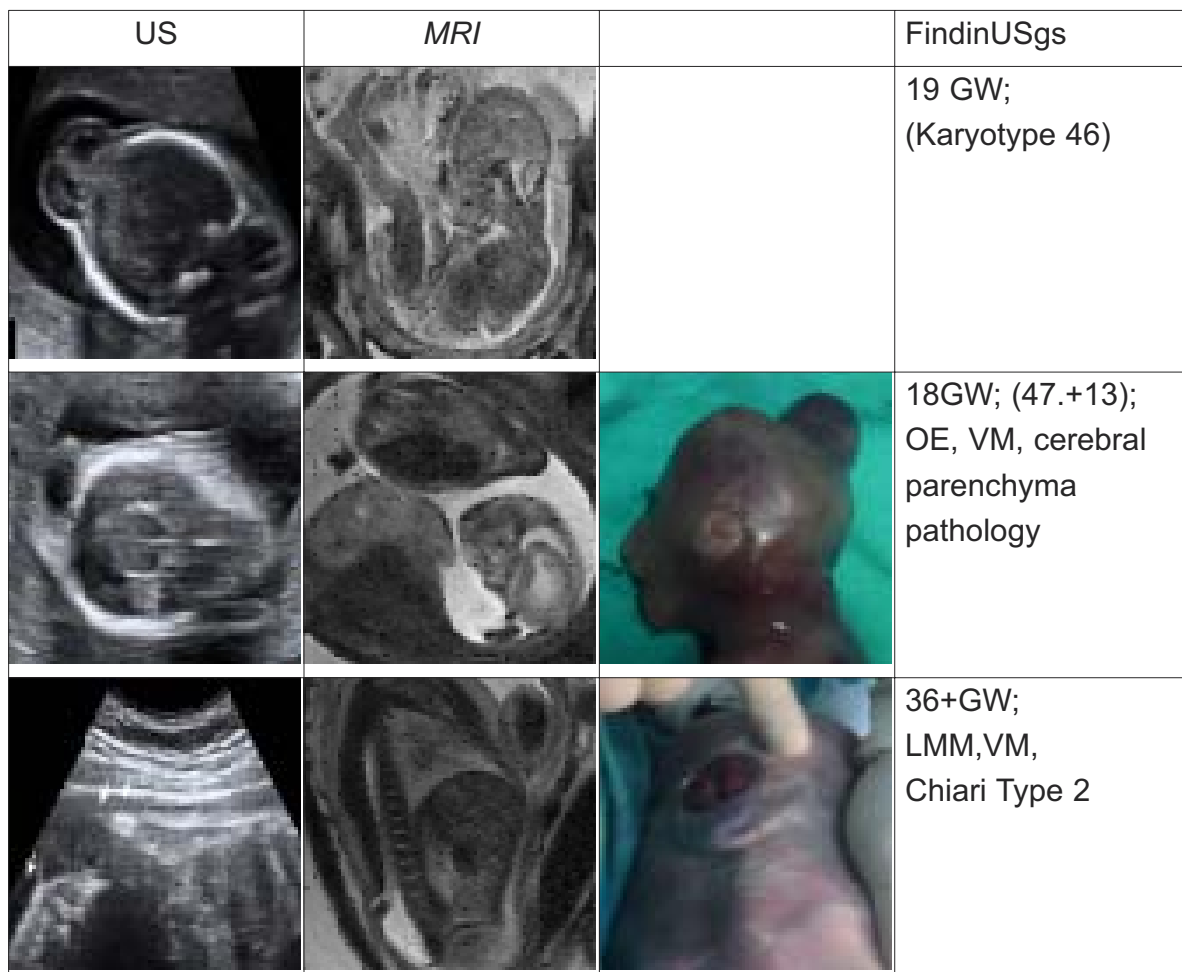

36+GW;

LMM,VM,

Chiari Type 2
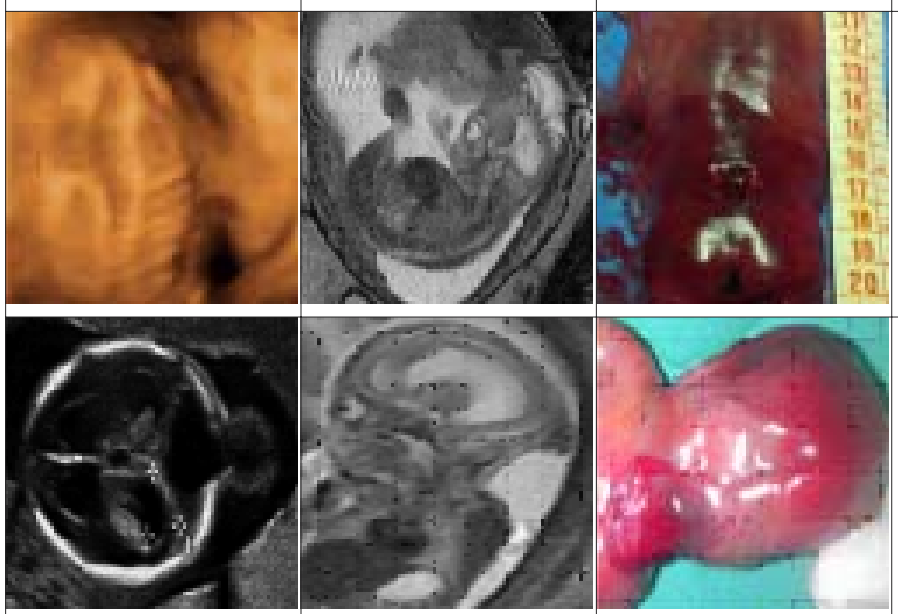

$19+G W$

OE, VM,

cerebellar atrophy

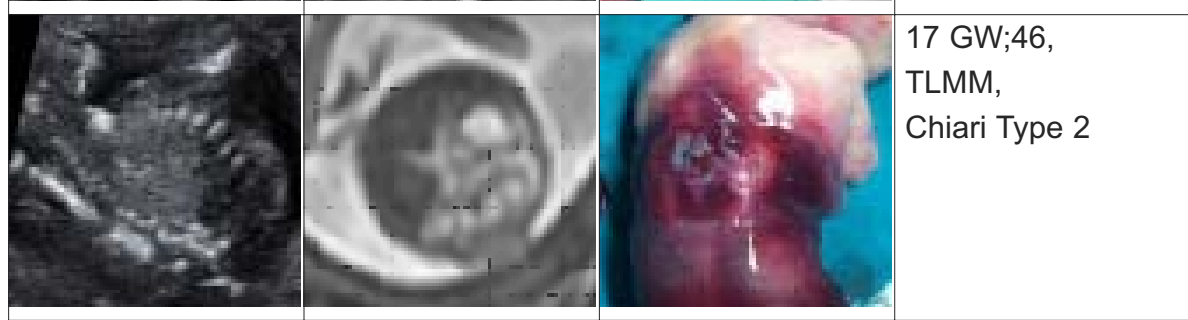

GW: Gestational week; LMM: Lumbar meningomyelocele; LSMM: Lumbosacral meningomyelocele; MRI: Magnetic Resonance Imaging; NTD: Neural tube defect; OE: Occipital encephalocele, OMM: Occipital meningomyelocele; TLMM: Thoracolumbar meningomyelocele; US: Ultrasound; VM: Ventriculomegaly. 


\section{Discussion}

The prevalence of NTDs was 11.4 per 10000 births (48/42000) in Northwestern Turkey. Lumbosacral spinal bifida (SB) and encephalocele were the most common forms. The obesity and low FA intake have a role in the occurrence of NTDs. However, serum levels of FA, vit B12, Zn of NTDaffected mothers were not different in comparison to normal. The prevalence rate of homozygous MTHFR c.677C > T SNP was $15 \%$ among NTD mothers. In terms of ultrasonographic signs of fetal NTDs, the most common signs were lemon sign (68\%) and ventriculomegaly (68\%). Chiari type II malformation was observed $32 \%$ of the NTDs. One of the four NTDs $(25 \%)$ had an additional anomaly.

The incidence of NTDs in the northwestern part was lower than those in other parts $(0.3 \%)$ of Turkey. These numbers range from $0.46 \%$ to $0.27 \%$ in different countries (1113). The importance of the environmental factors on the occurrence of NTD was confirmed. The rates of NTD (4.39 per 1000 births) and anencephaly (2.46 per 1000 births) after the Chernobyl accident was increased (3). Although no significant relationship with maternal age or gravidity was supported in our study but the role of obesity on the occurrence of NTDs was found to be unavoidable $(7,8,13)$. Higher dose prenatal FA intake for the women with diabetes, obesity, malabsorption and those using antiepileptic drugs is inevitable (14). Nevertheless, not all cases of NTD are preventable by increasing the folate intake (15).

Although several studies reported low maternal serum FA, vit B12 and Zn levels among NTD- affected pregnancies, our results which come from a low NTD-rate area were in line with the studies which showed a lack of this correlation.

The epidemiological study in a low rate area reported no association between maternal serum folate $(4.13-4.28 \mathrm{ng} / \mathrm{ml})$, vit B12 (482.8-520.3 pg/ml) and the NTD risk (5). Our study also found that the levels of folate levels and vit B12 were around (12.6-15.6 ng/ml) and (222.6-232 pg/ml), respectively. Although regional vit B12 levels were low, serum folate levels in our study were higher than those in literature. That may cause a low rate in NTDs with in our area. However, according to another study, the mean of maternal serum zinc levels in the NTDs $(835.6+/-333.8 \mu \mathrm{g} / \mathrm{L})$ was significantly lower than the controls' $(1035.7+/-299.8 \mu \mathrm{g} / \mathrm{L})(6)$. Serum zinc levels were found to be $(153.2 \pm 77.2)$ versus $(159 \mathrm{mg} / \mathrm{dl} \pm 45.7)$ with no significance in our study.

The relationship between MTHFR c.677C $>$ T SNP and NTD is not clear. The prevalence of homozygous MTHFR c. $677 \mathrm{C}>\mathrm{T}$ SNP among NTD affected mothers was $15 \%$ in our study. The 677T-C mutation might not be responsible for a large percentage of folic-acid preventable NTD cases (16). Another study suggested that vit B12 fortification might reduce NTDs more than FA fortification alone (17). Consuming a folic acid supplement was affected by less acculturation in which less likely reporting consumption of supplements (18). In studies conducted before the initiation of food fortification, folic acid supplementation provided protection against NTDs. This strong FA protection effect against NTD might also depend on the initial NTD rate (15). Some newer post fortification studies could not demonstrate this relationship (19).

The study of Nicolaides et al showed that the lemon sign in the 54 of 70 fetuses (77\%) with open SB at 16-23 GW and the banana sign was met in $12 / 21(57 \%)$ fetuses (20). In addition, the cerebellum could not be displayed in $8(11 \%)$ cases ultrasonographically. Another study found that $98 \%$ of open SB fetuses show the lemon sign until $24 \mathrm{GW}, 95 \%$ of open SB fetuses with cerebellar abnormalities irrespective of gestational age (21).

On the basis of these data, a new approach is proposed for the investigation of patients at high risk for fetal open SB that is computer aided detection of SB. The curvature scale space features of fetal skulls, such as lemon sign, extracted from ultrasound images were studied firstly (22).

Fetal MRI may be useful for SB fetuses in the evaluation of fetal outcome in terms of ambulation, bladder functions, scoliosis or dysphagia (23). In this study, fetal MRI, which was an effective, noninvasive means of assessing fetal CNS anatomy, was performed in only 6 fetal NTDs to analyze the abnormalities in corpus callosum and posterior fossa anatomy (24).

According to prenatal and postnatal evaluations, 12 out of 48 fetuses with NTDs $(25 \%)$ had additional anomalies in our study. On the other hand, the rate of additional anomalies among NTDs was reported to be $32 \%$ in an observational study from the southern part of Turkey (25).

\section{Strengths and limitations}

The strength of this prospective cohort study is to analyze fetal NTD profile at a local region in Turkey. As a limitation of this small sized study, the number of controls could be increased to gain more statistical power in bioassays of FA, vit $\mathrm{B} 12$ and $\mathrm{Zn}$ under the light of local dietary data.

\section{Conclusion}

The northwestern region appeared to be a relatively low prevalence area of Turkey for fetal neural tube defects. Any association with maternal serum folic acid, vit B12 and zinc levels could not be shown in this region.

: Acknowledgement: We acknowledge the mothers who are part of the study.

Conflict of Interests: We declare that we have no conflict of interest with respect to the research and authorship and/or publication of this article.

Financial Disclosure: The authors have no financial relationship relevant to this article to disclose. 
Author contributions: E Turhan: Data collection; FG Varol: Project Development, Manuscript writing; $H$ Gürkan: Methodology; NC Sayın: Manuscript editing.

Ethics Committee Approval:2013/27

Informed Consent: Obtained

\section{References}

1. Marco P, Merello E, Capra V. Prevalance, Pathogenesis and Prevention of Neural Tube Defects. In: Alberich Klein (ed), Neural Tube Defects. New York: Nova Science Publishers 2013.1-30.

2. Tuncbilek E, Boduroglu K, Alikasifoglu M. Neural tube defects in Turkey: prevalence, distribution and risk factors. Turk J Pediatr 1999;41(3):299-305

3. Mocan H, Bozkaya H, Mocan MZ, Furtun EM. Changing incidence of anencephaly in the eastern Black Sea region of Turkey and Chernobyl. Paediatr Perinat Epidemiol $1990 \mathrm{Jul} ; 4$ (3):264-268

4. Berry RJ, Li Z, Erickson D, Li S, Moore CA, Wang H et al. Prevention of Neural-Tube Defects with Folic Acid in China. NEJM 1999;341(20):1485-1490

5. Mills JL, Tuomilehto J, Yu KF, Colman N, Blaner WS, Koskela $\mathrm{P}$, et al. Maternal vitamin levels during pregnancies producing infants with neural tube defects. J Pediatr 1992;120 (6):863-871

6. Zeyrek D, Soran M, Cakmak A, Kocyigit A, İşcan A. Serum Copper and Zinc Levels in Mothers and Cord Blood of their Newborn Infants with Neural Tube Defects: A Case-control Study. Indian Pediatr 2009;46(8):675-680

7. Watkins ML, Rasmussen SA, Horein MA, Botto LD, Moore CA. Maternal obesity and risk for birth defects. Pediatrics 2003;111(5 Pt 2):1152-8

8. Hendricks K, Nuno OM, Suarez L, Larsen R. Effects of hyperinsulinemia and obesity on risk of neural tube defects among Mexican Americans. Epidemiology 2001; 12(6):630-635

9. Yu Y, Wang F, Bao Y, Lu X, Quan L, Lu P. Association between MTHFR gene polymorphism and NTDs in Chinese Han population. Int J Clin Exp Med 2014;15:7(9):29012906

10. Varol FG, Turhan E, Sayın NC, Kırıcı MY, Genchellac H. The role of prenatal magnetic resonance on sonographically-confirmed central nervous abnormalities. $24^{\text {th }}$ World Congress on Ultrasound in Obstetrics and Gynecology Electronic poster abstracts, P04.16

11. Lary JM, Edmonds LD. Prevalence of Spina Bifida at Birth-United States, 1983-1990: a comparison of two surveillance systems. MMWR 1996;45:15-26

12. Kandasamy V, Subramanian M, Rajilarajendran H, Ramanujam S, Saktivel S, Sivaanandam R. A study on the incidence of neural tube defects in a tertiary care hospital over a period of five years. J Clin Diagn Res 2015;9(7):
QC01-4

13. Talebian A, Soltani B, Sehat M, Zahedi A, Noorian A, Talebian M. Incidence and risk factors of neural tube defects in Kashan, central Iran. Iran J Child Neurol 2015;9 (3):50-6

14. Kennedy D, Koren G. Identifying women who may benefit from higher doses of folic acid in pregnancy. Can Fam Physician 2012;58 (4):394-397

15. Heseker HB, Mason JB, Selhub J, Rosenberg IH, Jacques PF. Not all cases of neural-tube defect can be prevented by increasing the intake of folic acid. Br J Nutr 2009; 102:173-180

16. Posey DL, Khoury MJ, Mulinare J, Adams MJ, Ou CY. Is mutated MTHFR a risk factor neural tube defects? Lancet 1996 Mar 9; 347 (9002):686-687

17. Thompson MD, Cole DE, Ray JG. Vitamin B-12 and neural tube defects: The Canadian experience. Am J Clin Nutr 2009;89(2): 697S-701S

18. Marchetta CM, Hamner HC. Blood folate concentrations among women of childbearing age by race/ethnicitiy and acculturation, NHANES 2001-2010. Matern Child Nutr 2016;12(1):39-50

19. Viswanathan M, Treiman KA, Kish-Doto J, Middleton JC, Coker-Schwimmer EJ, Nicholson WK. Folic Acid supplementation for the prevention of Neural Tube Defects an updated evidence report and systematic review for the US preventive services task force. JAMA 2017;317(2):190203

20. Nicolaides KH, Campbell S, Gabbe SG, Guidetti R. Ultrasound screening for spina bifida: cranial and cerebellar signs. Lancet 1986;12;2 (8498):72-4

21. Van den Hof MC, Nicolaides KH, Campbell J, Campbell S. Evaluation on the lemon and banana signs in one hundred thirty fetuses with open spina bifida. Am J Obstet Gynecol 1990;162 (2):322-327

22. Konur U, Gürgen FS, Varol F, Akarun L. Computer aided detection of spina bifida using nearest neighbor classification with curvature scale space features of fetal skulls extracted from ultrasound images. Knowledge-Based Systems 2015;85:80-95

23. Mangels KJ, Tulipan N, Tsao LY, Alarcon J, Bruner JP. Fetal MRI in the evaluation of intrauterine myelomeningocele. Pediatr Neurosurg 2000;32(3):124131

24. Chao TT, Dashe JS, Adams RC, Keefover-Hicks A, McIntire DD, Twickler DM. Fetal spine findings on MRI and associated outcomes in children with open neural tube defects. AJR Am J Roentgenol 2011;197: W956-961

25. Toru HS, Sanhal YC, Uzun CO, Ocak GA, Mendilcioğlu İ, Karaveli FŞ. Associated anomalies with neural tube defects in fetal autopsies. J Matern Fetal Neonatal Med 2016;29(5):798-802 